\title{
Clinical characteristics of Major Depressive Disorder run in families - A community study of 933 mothers and their children
}

\author{
Andrea Schreier ${ }^{\text {a }}$, Michael Höfler ${ }^{a}$, Hans-Ulrich Wittchen ${ }^{\text {a,b }}$, Roselind Lieb ${ }^{\text {a, }}{ }^{*}$ \\ a Max Planck Institute of Psychiatry, Clinical Psychology and Epidemiology Unit, Kraepelinstrasse 2, \\ 80804 Munich, Germany \\ b Technical University of Dresden, Clinical Psychology and Psychotherapy, Mommsenstrasse 3, \\ 01187 Dresden, Germany
}

\begin{abstract}
The familial aggregation of Major Depressive Disorder (MDD) has been repeatedly demonstrated. Several studies have investigated associations between various clinical characteristics of MDD in probands and overall rates of MDD in relatives. Few studies, however, have considered the familial aggregation of clinical characteristics of MDD. The aim of the present report is to examine motheroffspring associations of a variety of clinical characteristics of MDD in a general population sample. Data were derived from baseline and 4-year-follow-up data of 933 adolescents and their biological mothers of the Early Developmental Stages of Psychopathology (EDSP) study, a prospectivelongitudinal community study. MDD and its characteristics were assessed with the Munich-Composite International Diagnostic Interview. We found that children of mothers who had a lifetime history of severe MDD and high number of symptoms, high impairment and/or melancholia, revealed elevated odds of MDD regarding the same characteristics as their mothers (ORs between 5.2 and 13.9). The observed associations did not differ by the children's sex. DSM-IV melancholia and severity as well as impairment were found to aggregate within families. This finding can be interpreted as a validation of the DSM-IV MDD severity subtypes as well as of the melancholic specifier. Severe and melancholic MDD reveal a considerable high degree of familiar aggregation making the search for mechanisms involved in the familiar transmission of these forms of MDD particularly promising.
\end{abstract}

Keywords: Major depressive disorder; Clinical characteristics; Familial aggregation

\section{Introduction}

Accumulating research over the last decades suggests phenotypic as well as etiologic heterogeneity of Major Depressive Disorder (MDD) (Barondes, 1999; Merikangas et al., 2002). For example, the clinical presentation of MDD can vary considerably with respect to symptomatology, age at onset, duration, or severity. In family- genetic studies, more homogeneous subgroups of mental disorders can be identified through studying the patterns of familial aggregation associated with different clinical features of MDD (Weissman et al., 1986a,b; Sullivan et al., 2000; Merikangas et al., 2002).

The overall familial aggregation of MDD has been repeatedly demonstrated (Klein et al., 2001; Lieb et al., 2002b; for a review, see Sullivan et al., 2000). Yet, the question whether this aggregation differs for various MDD subgroups has yielded more contradicting research results. Most studies have examined whether certain clinical characteristics of MDD in the probands predicted MDD in relatives. For example, Lieb et al. (2002a) demonstrated that recurrence and impairment as clinical characteristics of MDD in adolescents were associated with elevated rates of MDD in their parents (see also Bland et al., 1986; Weissman et al., 
1986a,b; Maier et al., 1991; Kendler et al., 1994, 1999; Wickramaratne et al., 2000; Klein et al., 2002). Other characteristics that have been studied in family or twin studies are age at onset (Mendlewicz and Baron, 1981; Gershon et al., 1982; Weissman et al., 1984; Bland et al., 1986; McGuffin et al., 1987; Price et al., 1987; Stancer et al., 1987; Weissman et al., 1988; Kupfer et al., 1989; Maier et al., 1991; Kendler et al., 1994; Harrington et al., 1997; Wickramaratne and Weissman, 1998; Kendler et al., 1999; Wickramaratne et al., 2000; Klein et al., 2002; Lieb et al., 2002a), severity (Klein et al., 2002; Lieb et al., 2002a; Hammen and Brennan, 2003), treatment (Weissman et al., 1986a,b; Kendler et al., 1994; Klein et al., 2002; Lieb et al., 2002a), comorbidity (Weissman et al., 1986a,b; Kendler et al., 1994; Lieb et al., 2002a), as well as specific depressive symptomatology, for example, suicidality or melancholia (Leckman et al., 1984a,b; Weissman et al., 1986a,b; Klein, 1990; Kendler, 1997; Kendler et al., 1994, 1999; Klein et al., 2002; Lieb et al., 2002a).

One important but rather understudied aspect in this context is whether certain characteristics of MDD aggregate within families. If specific clinical variables of MDD can be identified to „breed true“, this could mark distinct subgroups of MDD which are transmitted in families. This is an extension of the research described above insofar as here clinical characteristics are taken into consideration in all the family members. However, this requires detailed information on various aspects of MDD not only in the probands but also in the relatives. We identified few studies dealing with this question. Klein et al. (2002), for example, found no familial aggregation of the MDD features severity, recurrence, chronicity, early onset, impairment, melancholia, suicidality, and treatment among adolescents and their first-degree relatives with MDD. Leckman et al. (1984b) were not able to demonstrate that various subtypes of MDD „,breed true“ within families. With respect to an early onset of MDD, Wickramaratne and Weissman (1998) found elevated rates of childhood-onset MDD only in children of parents with early-onset of MDD (see also Weissman et al., 1986a,b, 1988; Maier et al., 1991). Between twins concordant for MDD, Kendler et al. (1992) reported significant but minor relations as regards age at onset, treatment seeking, impairment, number of symptoms and suicidal ideation, but no relations as regards melancholia (Kendler, 1997).

Several limitations of previous studies must be considered: Only two (Kendler et al., 1992; Klein et al., 2002) included a variety of characteristics simultaneously. As most of these studies were based on clinical samples, extrapolation to the general population cannot be made (Kendler, 1995). Furthermore, in the majority of the studies, family history information was used rather than direct diagnostic interviews. In addition, the definitions of MDD characteristics vary considerably among studies.

The aim of the present report is to study the familial aggregation of MDD by taking into consideration different clinical characteristics of MDD. We examined associations between clinical characteristics of MDD in mothers and their children from a representative community sample. Our analyses were restricted to mothers and their children because for other family members no direct diagnostic information allowing for detailed information on characteristics of MDD was available. This paper is an extension of our previously published results in that we consider characteristics of MDD in probands as well as in relatives (mothers). In our previous work, overall rates of familial MDD associated with certain characteristics of MDD in the probands were examined (Lieb et al., 2002a). The specific questions are as follows: (1) How frequent are MDD and its characteristics in the mothers and their children, and (2) do mothers and children with MDD resemble each other with respect to characteristics of MDD, i.e., can we find mother-offspring associations between clinical characteristics of MDD? 


\section{Methods}

\subsection{Design}

Data come from the Early Developmental Stages of Psychopathology study (EDSP). The EDSP is a prospective- longitudinal survey to collect data on the prevalence and incidence, familial and other risk factors, comorbidity, and course of mental disorders in a representative sample of originally 3021 participants 14-24 years of age. The study consists of a baseline and two follow-up investigations. The parents of the 14- to 17-year-olds at baseline were additionally assessed in a separate parent survey. Detailed descriptions of the EDSP design and field procedures are reported elsewhere (Wittchen et al., 1998a; Lieb et al., 2000).

\subsection{Sample}

The EDSP builds on a random population sample from the 1994 government population registries of residents in Munich, Germany. As the study was designed with special interest in early developmental stages of psychopathology, 14- to 15-year-olds were sampled at twice the probability of 16- to 21-year-olds, and 22- to 24-yearolds were sampled at half this probability. Details about the sampling, representativeness, and sociodemographic characteristics of the whole EDSP-sample have been reported (Wittchen et al., 1998a; Lieb et al., 2000). At baseline (T0), the response rate for the study sample of 14- to 17-year-olds (the „younger cohort“) was 74.3\%. The first follow-up study (T1) was conducted an average of 19.7 months (range $=15-25.6$ months; $88.0 \%$ response rate among baseline responders), and the second follow-up study (T2) was conducted an average of 42 months (range $=34-50$ months; $83.8 \%$ response rate among baseline responders) after the baseline investigation.

In the parent survey, information about early development and familial psychopathology was obtained in direct diagnostic interviews with the parents of the younger cohort (Lieb et al., 2000). Fathers were interviewed only if the mother was not available (deceased or not located). The parents of 1053 adolescents were interviewed directly (in 1026 cases the mother, in 27 cases the father; 86.0\% response rate among T1 responders). The predominant causes of non-response among parents were their refusal to participate (12.9\%), researchers' failure to contact parents $(0.7 \%)$, and parents' lack of time (0.5\%; see Lieb et al., 2000$)$. The study sample for the current report consisted of all adolescents who had completed the second follow-up and whose biological mothers had participated in the parent survey $(\mathrm{N}=933)$. These adolescents represent the offspring for the following report. For a detailed overview of the EDSP study design including the sample of the present report see Höfler et al. (2005).

We decided to limit the analyses to this sample for the following reasons: (1) information on clinical characteristics of MDD was available only for parents directly interviewed in the parent investigation, (2) of these 1053 interviews only 27 were conducted with fathers and eight with non-biological mothers. To make interpretation of the results clearer we included only the biological mothers and their adolescents, and (3) only those adolescents were included who completed the second follow-up investigation in order to take advantage of the information of the complete follow-up period. Analyses were conducted to evaluate whether there was a systematic drop-out based on DSM-IV diagnoses of affective, anxiety or substance use disorders or sociodemographic variables from 1395 individuals of the younger cohort at baseline to 933 in the sample of the present report. It could be demonstrated that no major bias is expected (Höfler et al., 2005; Schreier, 2005).

\subsection{Assessment}


Adolescents and their parents were assessed with the computer-assisted version of the Munich-Composite International Diagnostic Interview (DIA-X/M-CIDI; Wittchen and Pfister, 1997), an updated version of the World Health Organization's (WHO) Composite

International Diagnostic Interview version 1.2 (World Health Organization, 1990). Diagnostic findings - according to the explicit diagnostic criteria of the Diagnostic and Statistical Manual of Mental Disorders, 4th revision (DSM-IV; American Psychiatric Association [APA], 1994) - were obtained by using the M-CIDI/DSM-IV algorithms. For a detailed discussion of the M-CIDI, see Wittchen et al. (1998b) and Lachner et al. (1998). The reliability and validity of the M-CIDI and its assessment of MDD, along with descriptions of the M-CIDI format and coding conventions, have been presented by Wittchen et al. (1998b) and Reed et al. (1998). In all assessments, the M-CIDI was supplemented by a separate booklet that included several scales and questionnaires to assess psychological constructs relevant to the study. All interviews were administered by highly trained clinical interviewers. Most interviews were carried out in the homes of the adolescents and their parents. A detailed overview and characterization of the constructs and assessment methods have been provided elsewhere (Höfler et al., 1999; Wittchen et al., 1999; Lieb et al., 2000). At baseline, the lifetime version of the MCIDI was used. At each of the follow-up assessments, we applied the M-CIDI interval version, which refers to the time period between the last and the present interview. For the study sample to be considered in the following report, the complete lifetime status until T2 was assessed from the aggregation of information obtained from the T0, T1, and T2 interviews.

\subsection{Assessment of MDD and MDD characteristics}

All the diagnostic information on MDD and its characteristics in the adolescents and their mothers was collected within the M-CIDI depression section (see Oldehinkel et al., 1999). Diagnoses were obtained by using the M-CIDI diagnostic package for DSM-IV diagnostic algorithms. The clinical characteristics of MDD were defined as follows: (1) Severity of MDD symptoms according to DSM-IV specifications allowing for subtyping mild, moderate, and severe forms. In the analyses, severe MDD was compared to the collapsed category of mild and moderate MDD; (2) recurrence as more than one episode of MDD; (3) early onset based on self-reported age at onset of depressive symptoms (cut-offs: adolescents: before age 15; mothers: before age 30); (4) impairment in daily life and activities due to MDD during the worst episode. The answers „very much“ and „a lot“ were collapsed and compared to the combined category of „not at all“ and „somewhat“; (5) treatment of MDD by a doctor, another specialist, or in hospital; (6) suicidality as presence of suicidal attempts, ideas, or plans; (7) melancholia according to DSM-IV; (8) comorbidity as presence of any DSM-IV anxiety disorder (lifetime), including panic disorder, agoraphobia, phobia NOS, social phobia, specific phobia, generalized anxiety disorder, obsessive compulsive disorder, and posttraumatic stress disorder; and (9) at least 7 symptoms versus 5 or 6 symptoms according to the DSM-IV criteria for MDD during the worst episode (range = 5-9 among MDD cases).

In the following, mothers with MDD who fulfilled the conditions for a certain MDD characteristic will be referred to as „MDD Charac + “ mothers. Mothers who fulfilled the criteria for MDD but did not fulfill the definition of the respective characteristic will be referred to as „MDD Charac -“ mothers.

\subsection{Statistical analyses}


Data were weighted to consider different sampling probabilities as well as systematic nonresponse at baseline and first follow-up according to age, sex, and geographic distribution. For our analyses we used the Stata software package (StataCorp., 2003) and applied the Huber-White sandwich matrix for robust estimates of confidence intervals in the case of weighted data (Royall, 1986).

As the aim was to examine the degree to which maternal characteristics of MDD predict characteristics of MDD in children, the maternal status regarding MDD and characteristics of MDD was the independent variable. Diagnostic outcomes were the offspring's cumulative lifetime incidence rates of MDD and lifetime presence of MDD characteristics (assessed at T0, T1, and T2).

The associations between maternal MDD characteristics and MDD characteristics in children were estimated with odds ratios (ORs) from logistic regressions (McCullagh and Nelder, 1989). The reference group consisted of those children with MDD who did not fulfill the criteria for the particular characteristic.

Sex and age of offspring were controlled for in all analyses. All analyses were repeated by additionally controlling for sociodemographic variables in mothers. This was done to see to what extent these variables may alter the observed associations. To examine possible gender heterogeneity in the differences, we additionally assessed interactions with sex of offspring. Throughout the paper, a p-value $<0.05$ was considered as statistically significant.

\section{Results}

\subsection{Lifetime prevalence of MDD and frequency of MDD characteristics in mothers and children}

About one fifth of the mothers $(\mathrm{N}=188$; weighted percentage $[\% \mathrm{w}]=19.5$; $95 \%$ confidence interval $[\mathrm{CI}]=16.9-22.4)$ and about $14 \%$ of the adolescents $(\mathrm{N}=126 ; \% \mathrm{w}=13.9 ; 95 \% \mathrm{CI}=$ 11.5-16.5) reported to have ever fulfilled the criteria for MDD. MDD was more common in female than in male offspring $(17 \%$ vs. $11 \%$; OR $=1.7 ; 95 \% \mathrm{CI}=1.1-2.7)$. There were $\mathrm{N}=$ $33(\% \mathrm{w}=3.6 ; 95 \% \mathrm{CI}=2.3-5.2)$ mother-child pairs affected by MDD.

In Table 1, the frequencies of MDD characteristics are presented for mothers and their children. For most characteristics, the rates are similar in mothers and children. For example, more than $80 \%$ of the mothers and children With MDD reported that they were impaired by the symptoms, and about 50\% also fulfilled the lifetime criteria for any comorbid DSM-IV anxiety disorder. However, only $24.2 \%$ of the children, as compared to almost two thirds of the mothers, had received treatment of their depression. Male and female offspring did not differ with respect to the frequency of the different MDD characteristics.

\subsection{Sociodemographic characteristics of mothers and children}

With respect to their mean age, mothers with MDD (45.8 years) and those without MDD (46.9 years) hardly differed; but with respect to their current living situation, they considerably differed: $84.7 \%$ of the mothers without and $69.8 \%$ of the mothers with MDD lived with a partner. The lifetime unemployment rate was $22.1 \%$ among mothers without and $30.6 \%$ among mothers with MDD. We found no differences in the educational level (higher education [Abitur]: $26.5 \%$ of the mothers without and $27.7 \%$ of those with MDD) and in the current employment status (employed: $74.7 \%$ of mothers without and $72.7 \%$ of those with 
MDD). The children's sex did not differ by maternal MDD status (the ratio of female children was 50.0\% among mothers without and 55.8\% among those with MDD). We found almost no difference in the mean age at second follow-up between the children of mothers without (18.8 years) and those of mothers with MDD (18.6 years).

\subsection{Associations between MDD characteristics in mothers and children}

The rates of MDD with each of the characteristics in the children are presented in Table 2. We differentiated between children of mothers with MDD but without the particular characteristic (MDD Charac -) and children of mothers with MDD and with the respective characteristic (MDD Charac +).

The first line, for example, indicates that severe MDD was present in $4.5 \%$ of the children of mothers with mild or moderate MDD (but not the severe subtype) and in $14.3 \%$ of the children of mothers with severe MDD. This means that 95.5\% of the children of MDD Charac - and $85.7 \%$ of the children of MDD Charac + mothers either had MDD that was not classified as severe or did not fulfill the criteria for MDD at all.

We conducted logistic regression analyses to evaluate whether the observed rates of MDD with the respective characteristic differed between children of MDD Charac - and those of MDD Charac + mothers. These analyses yielded elevated rates of MDD with the respective characteristic in children of mothers with than in those of mothers without the same characteristic for melancholia (7.9\% vs. 1.4\%; OR = 8.8; 95\% CI $=1.3-56.2)$ and impairment $(17.5 \%$ vs. $2.6 \%$; OR $=13.9 ; 95 \% \mathrm{CI}=1.1-188.6)$ but also for severity $(14.3 \%$ vs. $4.5 \%$; OR $=5.2 ; 95 \% \mathrm{CI}=1.1-24.8)$ and number of symptoms $(11.2 \%$ vs. $3.3 \%$; OR $=5.9 ; 95 \% \mathrm{CI}=$ 1.1-29.2).

The estimates remained relatively stable when we additionally controlled for maternal sociodemographic variables as presented in the last column of Table 2. Again, the ORs for severity, melancholia, and number of symptoms were clearly elevated. Only for impairment, the adjusted OR did not reach the required level of significance although the point estimate even slightly increased.

No significant interactions with sex of offspring were found, which suggests similar ORs for female and male offspring.

\section{Comment}

The goal of this study was to explore mother-offspring associations of MDD in a community sample, taking into account various phenotypic symptom characteristics. In this context, the special strengths of the EDSP study are the following: (1) As the children and their mothers were drawn from the general population, selection bias due to treatment seeking can be ruled out. (2) Direct and independent diagnostic interviews were conducted with all participants, excluding informant bias. (3)MDD and its characteristics were assessed in mothers and children with a standardized interview. (4) Detailed information on a variety of MDD characteristics in probands and their family members was available.

First, we could demonstrate that all of the characteristics of MDD examined (severity, number of symptoms, recurrence, early onset, suicidality, melancholia, treatment, impairment, comorbidity with anxiety disorders) occur frequently in both, mothers and their children. For most of these characteristics, rates are similar among 17- to 21-year-old children (mean age: 
18.5 years) and their mothers. This further supports the notion that the core phenotypic expressions of depression in general is quite similar among adolescents and adults (Roberst et al., 1995; Birmaher et al., 1996; Oldehinkel et al., 1999; Kessler et al., 2001; Lewinsohn et al., 2003, see, however, Weiss and Garber, 2003). We showed that about $50 \%$ of the mothers and children with MDD had at least one comorbid anxiety disorder, a finding that is in line with reports from other community studies (e.g., Angold et al., 1999; Axelson and Birmaher, 2001; Kessler, 2001; Andrade et al., 2003; see also Wittchen et al., 2000, 2003). Despite the general assumption that impairment and suicidality increase with age (Birmaher et al., 1996), we found high rates of suicidality ( $>40 \%)$ and impairment ( $>80 \%)$ in both groups. However, although almost two thirds of the mothers reported to have been in treatment for their depression, the respective rate in adolescents was only about $24 \%$. Similarly, the rate of melancholia found in mothers was about twice that in their children, indicating that a melancholic symptom profile might be more likely in higher ages. This would be in line with the report by Birmaher et al. (2004), who found more melancholic symptoms in adolescents than in children. Like other studies, we could not demonstrate different characteristics of MDD among male and female participants (Haarasilta et al., 2001; Lewinsohn et al., 2003).

The second part of this study dealt with the question of whether mothers and their children (given that both fulfill the lifetime criteria for MDD) resemble each other with respect to the clinical characteristics of the disorder. For severity as well as for both of the components used to define severity (i.e., number of symptoms and impairment, see DSM-IV, APA, 1994), the analyses revealed elevated rates of the same characteristic in the children of mothers with the respective feature, with high ORs ranging between 5.2 (severity) and 13.9 (impairment). In addition, higher rates of MDD with melancholic features were found in the children of mothers with melancholia (OR = 8.8). For the other characteristics (recurrence, early onset, suicidality, treatment, and comorbid anxiety disorder), no differences could be demonstrated.

Thus, we found mother-offspring associations for severity, number of symptoms, impairment, and melancholia. Maternal sociodemographics could not explain our associations, since controlling for these variables did not change the estimates of the ORs substantially. Although we found several significant associations, the broad confidence intervals did not allow us to assess the actual magnitudes of these relations. The rather small number of mother-child pairs with MDD prevented stable estimations. Also, the low statistical power indicates that for the negative findings the presence of moderate - and sometimes strong - associations cannot be ruled out. The failure to demonstrate associations with recurrence, treatment, and early onset might also be attributed to the fact, that the offspring by definition all have a fairly early onset and have not yet gone through a sufficient long period of risk for depression.

In the present study, we could demonstrate for mothers and their children an aggregation of clinical characteristics of MDD, whereas Klein et al. (2002) did not find any indication of a familial aggregation of MDD characteristics in young adults and their families. However, in line with the results of the present study, for example, Kendler et al. (1992) reported significant correlations in twins for impairment and number of symptoms. Although Weissman et al. (1984) and Wickramaratne and Weissman (1998) showed higher rates of early-onset MDD in relatives of probands who themselves reported an early onset of the disorder, this result was not found in the present study or in the analyses of Klein et al. (2002) or Maier et al. (1991). Thus, our results further underline the possibility that early-onset MDD might be associated with familial aggregation to a lower degree than it was previously assumed (see Sullivan et al., 2000; Merikangas et al., 2002). However, cut-off points for early-onset MDD vary considerably among and also within studies. For example, our cut-off point was set at age 30 for mothers and 15 for offspring. Due to the relatively young age of 
the latter, the age distribution was truncated, leaving open the possibility for early-onset MDD to aggregate in families if a later cut-off point is chosen. To our knowledge, our results are compared to those from previous studies - the only ones based solely on direct interviews with probands and family members in a representative community sample.

Because patterns of familial transmission have been conceptualized as one important validator of diagnostic subtypes (Robins and Guze, 1970; Andreasen et al., 1986; Weissman et al., 1986a,b; Kendell, 1989; Merikangas, 2002), our results can be interpreted as a validation especially of the DSM-IV (APA, 1994) subtype classifications of MDD according to severity and melancholia. In particular, melancholic features seem to „breed true“ within families because rates of melancholia were higher in children of mothers with melancholia than in children of mothers with most of the other characteristics (results are not presented but are available on request). This finding supports the conclusions of previous reports that the concept of melancholia has „some clinical utility and some validity“ (Rush and Weissenburger, 1994; Türkçapar et al., 1999; Klein et al., 2002; see, however, Parker, 2000; Joyce et al., 2002). As a rather surprising finding, we found no mother-offspring association for recurrent MDD, which, again, may have been due to the young age of our study sample. Under the assumption that children with prepubertal and adolescent onset MDD might have recurrent MDD in adulthood (Pine et al., 1998; Lewinsohn et al., 1999; Weissman et al., 1999; Fombonne et al., 2001), this result might be considered transient.

There is widespread agreement that, due to the phenotypic heterogeneity of MDD, research regarding the etiology (e.g., risk factors, pathophysiology, genetics) as well as the treatment of MDD requires, first of all, the definition of more homogeneous subgroups of MDD (e.g., Kaufman et al., 2001; Drevets, 2002; Merikangas, 2002). Such definitions might allow, for example, for the differentiation between familial and nonfamilial forms of the disorder. One possibility of doing so is to study the patterns of familial transmission. Our findings, which demonstrate for mothers and their children an aggregation of severity, impairment, number of symptoms, and melancholia, can be considered as an important step towards the search for more homogeneous subgroups, indicating that MDD with these features may constitute familial forms of the disorder.

However, it is crucial to realize that the characteristics that we examined are not mutually exclusive but overlapping. Faravelli et al. (1996), among others, reported that depressed patients with melancholia differed from those without melancholia regarding number of symptoms, severity of the disorder, and impairment. Thus, it remains unclear, for example, whether our observed aggregation is specific to melancholia or rather to symptom severity or impairment (see also Kendler, 1997; Türkçapar et al., 1999; Parker, 2000). Unfortunately, the number of mother-child pairs in this study was too small as to allow for additional multiple models needed to identify core features transmitted between mothers and their children (Merikangas, 2002).

The results of our study imply that, to a certain extent, an individual's familial background can influence the clinical characteristics of MDD displayed when a person has MDD. What mechanisms might be involved in this observed resemblance of MDD characteristics? Twin studies support the hypothesis that genetic factors may play some role, although familialenvironmental factors also seem to be of considerable importance (Kendler et al., 1992; McGuffin et al., 1996; Kendler, 1997). However, more research is needed to answer this question. 
With respect to the limitations of the study, the following issues have to be considered. First, information on MDD and its characteristics within families is available only on mothers and their children. Therefore, conclusions regarding the familial transmission of MDD and its characteristics are limited to mother-child associations. They are specific to the resemblance of characteristics of MDD between mothers and their children and do not allow for generalizations onto the transmission within families in general. Second, information of mothers and children is based on direct interviews only. Generally speaking a multimethod approach integrating information from different sources (e.g., best-estimate diagnoses based on direct interviews, informant information and medical records) may result in more valid diagnoses (Kendler and Roy, 1995). With respect to the clinical features of depression, however, Parker et al. (1992, 2003) demonstrated good agreement between self-reported and psychiatrist-rated measures but a clear lack of validity regarding reports of family members. Therefore, we assume that using direct interview information only still allows for valid assessment of the clinical features of depression. Third, children have not passed through the entire risk period for onset of MDD. Therefore, the results cannot yet be considered as robust. It can be assumed that the inclusion of false-negative cases (i.e., children that have not yet developed MDD) resulted rather in an underestimation of the respective associations. Also, these results apply only to adolescents until the age of 21, as, so far, no data are available on the development afterwards.

In conclusion, mothers and their children with MDD tend to resemble each other regarding melancholia, impairment, severity, and number of symptoms. This finding might help to differentiate between familial and non-familial forms of MDD and might improve etiological research as well as intervention strategies. Further research should clarify possible core features transmitted within families as well as the mechanisms underlying this transmission.

Table 1

Frequencies of characteristics of MDD in mothers and children with MDD

\begin{tabular}{|c|c|c|c|c|c|c|c|c|c|c|c|c|}
\hline \multirow[t]{2}{*}{ MDD characteristic } & \multicolumn{3}{|c|}{ Mothers $(N=188)$} & \multicolumn{3}{|c|}{ Children total $(N=126)$} & \multicolumn{3}{|c|}{ Males $(N=47)$} & \multicolumn{3}{|c|}{ Females $(N=79)$} \\
\hline & $N$ & $\% \mathrm{w}$ & $95 \% \mathrm{CI}$ & $N$ & $\% w$ & $99 \% \mathrm{CI}$ & $N$ & $\% w$ & $95 \%$ C & $N$ & $\% w$ & $95 \% \mathrm{CI}$ \\
\hline Severity & 92 & 47.7 & $(40,0-55,4)$ & 46 & 39.5 & $(30,4-49,4)$ & 15 & 36.5 & $(22,0-54,0)$ & 31 & 41.3 & $(30.0-53.7)$ \\
\hline Recurrence & 79 & 42.3 & $(34.8-50.1)$ & 39 & 29.6 & $(21.7-38.9)$ & 12 & 27.0 & $(15.1-43.4)$ & 27 & 31.1 & $(21.3-43.0)$ \\
\hline Early onset & 60 & 31.5 & $(24.8-39.0)$ & 40 & 29.6 & $(21.8-38.9)$ & 16 & 33.8 & $(20.5-50,3)$ & 24 & 27.1 & $(17.9-38.7)$ \\
\hline Suicidality & 80 & 41.4 & $(34.0-49.2)$ & 60 & 44.8 & $(35.6-54.4)$ & 19 & 36.8 & $(23.2-52.9)$ & 41 & 49.6 & $(37.7-61.5)$ \\
\hline Melancholia & 89 & 48.5 & $(40.8-56.2)$ & 31 & 24.2 & $(16.9-33,3)$ & 11 & 20.0 & $(10.5-34.8)$ & 20 & 26.6 & $(17.1-38.9)$ \\
\hline Treatment & 121 & 63.9 & $(\$ 6.2-71.0)$ & 29 & 24.2 & $(16.6-33,8)$ & 9 & 24.8 & $(12,3-43,6)$ & 20 & 23.9 & (15.1-35.5) \\
\hline Comorbid anxiety disorder & 90 & 48.9 & $(41.2-56.7)$ & 66 & 49.0 & $(39.5-58.5)$ & 17 & 35.2 & $(21.7-51,6)$ & 49 & 57.3 & $(44.8-68.8)$ \\
\hline At least seven symptoms & 87 & 44.3 & $(36.8-52.1)$ & 44 & 37.8 & $(28.8-47.7)$ & 12 & 28.7 & $(15.7-46.6)$ & 32 & 43.3 & $(31.7-55.6)$ \\
\hline
\end{tabular}

N: number; \%w: weighted percentages; CI: confidence interval; severity: severe MDD according to DSM-IV; recurrence: more than one episode; early onset: onset of MDD symtoms before age 30 in mothers, age 15 in children; suicidality: presence of suicidal ideas, plans, or attempts; melancholia: melancholic features according to DSM-IV; treatment: treatment by doctor, another specialist, or in hospital; impeiment: self reported strong impeirment; comorbid anxiety disorder, presence of any DSM-IV anxiety disorder (lifetime); at least seven symptoms: symptoms during the worst episode, range 5-9 among MDD cases. 
Table 2

Rates of MDD with particular clinical characteristics in children according to maternal MDD characteristics

\begin{tabular}{|c|c|c|c|c|c|c|c|c|}
\hline \multirow[t]{2}{*}{ MDD characteristics in children } & \multicolumn{4}{|c|}{ Maternal MDD characteristic status } & \multirow{2}{*}{\multicolumn{2}{|c|}{$\begin{array}{l}\text { MDD Charac + vs. } \\
\text { MDD Charac - }\end{array}$}} & \multirow{2}{*}{\multicolumn{2}{|c|}{$\begin{array}{l}\text { MDD Charac + vs. } \\
\text { MDD Charac - }\end{array}$}} \\
\hline & \multicolumn{2}{|c|}{$\begin{array}{l}\text { MDD } \\
\text { Charac-a }\end{array}$} & \multicolumn{2}{|c|}{$\begin{array}{l}\text { MDD Charac } \\
+^{\mathrm{b}}\end{array}$} & & & & \\
\hline Severity ${ }^{c}$ & 4 & 4.5 & 10 & 14.3 & $5.2^{*}$ & $(1.1-24.8)$ & $5.9^{*}$ & $(1.2-27.9)$ \\
\hline Recurrence ${ }^{d}$ & 7 & 6.9 & 7 & 7.9 & 1.5 & $(0.3-7.0)$ & 1.4 & $(0.2-6.8)$ \\
\hline Early onset & 16 & 14.0 & 6 & 9.7 & 1.0 & $(0.1-5.4)$ & 1.0 & $(0.1-5.4)$ \\
\hline Treatment & 4 & 5.2 & 5 & 5.0 & 0.8 & $(0.1-4.8)$ & 0.8 & $(0.1-4.7)$ \\
\hline Impaiment & 1 & 2.6 & 25 & 17.5 & $13.9^{*}$ & $(1.1-188.6)$ & 15.3 & $(0.9-235.6)$ \\
\hline Comorbid anxiety disorder & 6 & 5.4 & 11 & 11.8 & 2.2 & $(0.4-9.9)$ & 2.1 & $(0.4-10.4)$ \\
\hline At least seven symptoms & 4 & 3.3 & 7 & 11.2 & $5.9^{*}$ & $(1.1-29.2)$ & $6.6^{*}$ & $(1.2-33.8)$ \\
\hline
\end{tabular}

N: number; \%w: weighted percentages $\mathrm{OR}$ : odds ratio; $\mathrm{C}$ : confldence interval; MDD Charac -: mothers with MDD without the respective characteristic; MDD Charac +: mothers with MDD with the respective characteristic.

OR 1: controlled for sex and age of children; OR 2: controlled for sex and age of children and the following matemal sociodemographic variables: age, living situation, unemployment, educational level, current employment.

${ }^{*}$ The total number of mothers in each group equals the total number of MDD mothers $(N=188)$ minus those with the respective characteristic as in Table 1. Example: for severity: $N=96=188-92$.

(b The total number of mothers in each group is identical with the respective numbers in Table 1 .

c Example 1:4.9\% of children of mothers with MDD but not the severe subtype had severe MDD, $14.3 \%$ of children of mothers with severe MDD had severe MDD.

${ }^{d}$ Example 2: 6.9\% of children of mothers with non-recurrent MDD had recurrent MDD, 7.9\% of children of mothers with recurrent MDD had recurrent MDD.

\section{Acknowledgements}

This work is part of the Early Developmental Stages of Psychopathology (EDSP) Study and is funded by the German Ministry of Research and Technology, Project Nos. 01 EB 9405/6 and 01 EB 9901/6, EB01016200 and 01EB0440. Part of the field work and analyses were also additionally supported by grants of the Deutsche Forschungsgemeinschaft (DFG) LA1148/1-1 and WI2246/1-1. Principal investigators are Dr. Hans-Ulrich Wittchen and Dr. Roselind Lieb. Core staff members of the EDSP group are: Dr. Kirsten von Sydow, Dr. Gabriele Lachner, Dr. Axel Perkonigg, Dr. Peter Schuster, Dipl.-Stat. Michael Höfler and Dipl.-Psych. Holger Sonntag, Dipl.-Psych. Tanja Brückl, Dipl.-Psych. Elzbieta Garczynski, Dr. Barbara Isensee, Dipl.-Psych. Agnes Nocon, Dr. Chris Nelson, Dipl.-Inf. Hildegard Pfister, Dr. Victoria Reed, Dipl.-Soz. Barbara Spiegel, Dipl.-Psych. Andrea Schreier, Dr. Ursula Wunderlich and Dr. Petra Zimmermann. Scientific advisors are Dr. Jules Angst (Zurich), Dr. Jürgen Margraf (Basel), Dr. Günther Esser (Potsdam), Dr. Kathleen Merikangas (NIMH, Bethesda) and Dr. Ron Kessler (Harvard, Boston) and Dr. Jim van Os (Maastricht). Furthermore, this study as part of the "Multi-site international comparison of unmet needs" was supported by a grant from the National Institute of Health (NIH; 303-7028).

\section{References}

- American Psychiatric Association. Diagnostic and statistical manual of mental disorders. 4th ed. Washington (DC): American Psychiatric Association; 1994.

- Andrade L, Caraveo-Anduaga JJ, Berglund P, Bijl RV, de Graaf R, Vollebergh W, Dragomirecka E, Kohn R, Keller M, Kessler RC, Kawakami N, Kilic C, Offord D, Üstün TB, Vicente B, Wittchen H-U. The epidemiology of major depressive episodes: Results from the International Consortium of Psychiatric Epidemiology (ICPE) Surveys. International Journal of Methods in Psychiatric Research 2003;12:3-22.

- Andreasen NC, Scheftner W, Reich T, Hirschfeld RMA, Endicott J, Keller MB. The validation of the concept of endogenous depression. A family study approach. Archives of General Psychiatry 1986;43:246-51.

- Angold A, Costello EJ, Erkanli A. Comorbidity. Journal of Child Psychology and Psychiatry, and allied Disciplines 1999;40:57-87.

- Axelson DA, Birmaher B. Relation between anxiety and depressive disorders in childhood and adolescence. Depression and Anxiety 2001;14:67-78. 
- Barondes SH. Report of the National Institute of Mental Health’s Genetics Workgroup. Biological Psychiatry 1999;45:559-602.

- Birmaher B, Ryan MD, Williamson DE, Brent DA, Kaufman J, Dahl RE, Perel J, Nelson B. Childhood and adolescent depression: a review of the past 10 years. Part I. Journal of the American Academy of Child and Adolescent Psychiatry 1996;35:1427-39.

- Birmaher B, Williamson DE, Dahl RE, Axelson DA, Kaufman J, Dorn LD, Ryan ND. Clinical presentation and course of depression in youth: does onset in childhood differ from onset in adolescence? Journal of the American Academy of Child and Adolescent Psychiatry 2004;43:63-70.

- Bland RC, Newman SC, Orn H. Recurrent and nonrecurrent depression. A family study. Archives of General Psychiatry 1986;43:1085-9.

- Drevets WC. Neuroimaging studies of mood disorders. In: Helzer JE, Hudziak JJ, editors. Defining psychopathology in the 21st century. Washington (DC): American Psychiatric Publishing, Inc.; 2002. p. 71-105.

- Faravelli C, Servi P, Arends JA, Strik WK. Number of symptoms, quantification, and qualification of depression. Comprehensive Psychiatry 1996;37:307-15.

- Fombonne E, Wostear G, Cooper V, Harrington R, Rutter M. The Maudsley long-term followup of child and adolescent depression. I. Psychiatric outcomes in adulthood. British Journal of Psychiatry 2001;179:210-7.

- Gershon ES, Hamovit J, Guroff JJ, Dibble E, Leckman JF, Sceery W, Targum SC, Nurnberger JI, Goldin LR, Bunnes Jr WE. A family study of schizoaffective, bipolar I, bipolar II, unipolar, and normal control probands. Archives of General Psychiatry 1982;39:1157-67.

- Haarasilta L, Marttunen M, Kaprio J, Aro H. The 12-month prevalence and characteristic of major depressive episode in a representative nationwide sample of adolescents and young adults. Psychological Medicine 2001;31:1169-79.

- Hammen C, Brennan PA. Severity, chronicity, and timing of maternal depression and risk for adolescent offspring diagnoses in a community sample. Archives of General Psychiatry 2003;60:253-8.

- Harrington R, Rutter M, Weissman M, Fudge H, Groothues C, Bredenkamp D, Pickles A, Rende R, Wickramaratne P. Psychiatric disorders in the relatives of depressed probands. I. Comparison of prepubertal, adolescent and early adult onset cases. Journal of Affective Disorders 1997;42:9-22.

- Höfler M, Lieb R, Perkonigg A, Schuster P, Sonntag H, Wittchen HU. Covariates of cannabis use progression in a representative population sample of adolescents: a prospective examination of vulnerability and risk factors. Addiction 1999;94:1679-94.

- Höfler M, Pfister H, Lieb R, Wittchen H-U. The use of weights to account for non-response and drop-out. Social Psychiatry and Psychiatric Epidemiology 2005;40:291-9.

- Joyce PR, Mulder RT, Luty SE, McKenzie JM, Sullivan PF, Abbott RM, Stevens IF. Melancholia: definitions, risk factors, personality, neuroedocrine markers and differential antidepressant response. Australian and New Zealand Journal of Psychiatry 2002;36:376-83.

- Kaufman J, Martin A, King RA, Charney D. Are child-, adolescent-, and adult-onset depression one and the same disorder? Biological Psychiatry 2001;49:980-1001.

- Kendell RE. Clinical validity. Psychological Medicine 1989;19:45-55.

- Kendler KS. Is seeking treatment for depression predicted by a history of depression in relatives? Implications for family studies of affective disorder. Psychological Medicine 1995;25:807-14.

- Kendler KS. The diagnostic validity of melancholic major depression in a population-based sample of female twins. Archives of General Psychiatry 1997;54:299-304.

- Kendler KS, Roy M-A. Validity of a diagnosis of lifetime major depression obtained by personal interview versus family history. American Journal of Psychiatry 1995;152:1608-24.

- Kendler KS, Neale MC, Kessler RC, Heath AC, Eaves LJ. Familial influences on the clinical characteristics of major depression: a twin study. Acta Psychiatrica Scandinavica 1992;86:371-8. 
- Kendler KS, Neale MC, Kessler RC, Heath AC, Eaves LJ. The clinical characteristics of major depression as indices of the familial risk of illness. British Journal of Psychiatry 1994;165:66-72.

- Kendler KS, Gardner CO, Prescott CA. Clinical characteristics of major depression that predict risk of depression in relatives. Archives of General Psychiatry 1999;56:322-7.

- Kessler RC. Comorbidity of depression and anxiety disorders. In: Montgomery SA, den Boer JA, editors. SSRIs in depression and anxiety. Chichester: Wiley; 2001. p. 87-106.

- Kessler RC, Avenevoli S, Merikangas KR. Mood disorders in children and adolescents: An epidemiologic perspective. Biological Psychiatry 2001;49:1002-14.

- Klein DN. Symptom criteria and family history in major depression. American Journal of Psychiatry 1990;147:850-4.

- Klein DN, Lewinsohn PM, Seeley JR, Rohde P. A family study of major depressive disorder in a community sample of adolescents. Archives of General Psychiatry 2001;58:13-20.

- Klein DN, Lewinsohn PM, Rohde P, Seeley JR, Curbin CE. Clinical features of major depressive disorder in adolescents and their relatives: impact on familial aggregation, implications for phenotype definition, and specificity of transmission. Journal of Abnormal Psychology 2002;111:98-106.

- Kupfer DJ, Frank E, Carpenter LL, Neiswanger K. Family history in recurrent depression. Journal of Affective Disorders 1989;17:113-9.

- Lachner G, Wittchen H-U, Perkonigg A, Holly A, Schuster P, Wunderlich U, Türk D, Garczynski E, Pfister H. Structure, content and reliability of the Munich-Composite International Diagnostic Interview (M-CIDI) substance use sections. European Addiction Research 1998;4:28-41.

- Leckman JF, Caruso KA, Prusoff BA, Weissman MM, Merikangas KR, Pauls DL. Appetite disturbance and excessive guilt in major depression. Archives of General Psychiatry 1984a;41:839-44.

- Leckman JF, Weissman MM, Prusoff BA, Caruso KA, Merikangas KR, Pauls DL, Kidd KK. Subtypes of depression - family study perspective. Archives of General Psychiatry 1984b;41:833-8.

- Lewinsohn PM, Rohde P, Klein DN, Seeley JR. Natural course of adolescent major depressive disorder: I. Continuity into young adulthood. Journal of the American Academy of Child and Adolescent Psychiatry 1999;38:56-63.

- Lewinsohn PM, Pettit JW, Joiner TE, Seeley JR. The symptomatic expression of major depressive disorder in adolescents and young adults. Journal of Abnormal Psychology 2003;112:244-52.

- Lieb R, Isensee B, von Sydow K, Wittchen H-U. The early developmental stages of psychopathology study (EDSP): a methodological update. European Addiction Research 2000;6:170-82.

- Lieb R, Isensee B, Höfler M, Wittchen H-U. Parental depression and depression in offspring: evidence for familial characteristics and subtypes. Journal of Psychiatric Research 2002a;36:237-46.

- Lieb R, Isensee B, Höfler M, Pfister H, Wittchen H-U. Parental major depression and the risk of depressive and other mental disorders in offspring: a prospective-longitudinal community study. Archives of General Psychiatry 2002b;59:365-74.

- Maier W, Lichtermann D,Minges J, Heun R, Hallmayer J, Klingler T. Unipolar depression in the aged: determinants of familial aggregation. Journal of Affective Disorders 1991;23:53-61.

- McCullagh P, Nelder JA. Generalized linear models. 2nd ed. New York (NY): Chapman \& Hall; 1989.

- McGuffin P, Katz R, Bebbington P. Hazard, heredity and depression. A family study. Journal of Psychiatric Research 1987;21:365-75.

- McGuffin P, Katz R, Watkins S, Rutherford J. A hospital-based twin register of the heritability of DSM-IV unipolar depression. Archives of General Psychiatry 1996;53:129-36.

- Mendlewicz J, Baron M. Morbidity risks in subtypes of unipolar depressive illness: differences between early and late onset forms. British Journal of Psychiatry 1981;139:463-6. 
- Merikangas KR. Implications of genetic epidemiology for classification. In: Helzer JE, Hudziak JJ, editors. Defining psychopathology in the 21st century. Washington (DC): American Psychiatric Publishing, Inc.; 2002. p. 195-209.

- Merikangas KR, Chakravarti A, Moldin SO, Houman A, Blangero J, Burmeister M, Crabbe Jr JC, Cepaulo Jr JR, Foulks E, Freimer NB, Koretz DS, Lichtenstein W, Mignot E, Reiss AL, Risch NJ, Takahashi JS. Workgroup reports: NIMH strategic plan for mood disorders research. Future of genetics of mood disorders research. Biological Psychiatry 2002;52:45777.

- Oldehinkel A, Wittchen H-U, Schuster P. Prevalence, 20-month incidence and outcome of unipolar depressive disorders in a community sample of adolescents. Psychological Medicine 1999;29:655-68.

- Parker G. Classifying depression: should paradigms lost be regained? American Journal of Psychiatry 2000;157:1195-203.

- $\quad$ Parker B, Boyce P, Mitchell P, Hadzi-Pavlovic D, Wilhelm K, Hickie I, Brodaty H. Comparison of clinician rated and family corroborative witness data for depressed-patients. Journal of Affective Disorders 1992;24:25-34.

- Parker G, Gladstone G, Mitchell P, Welham K, Malhi G, Loo C. Valid assessment of the clinical features of depression by relatives appears to slip under the RADAR. Australian and New Zealand Journal of Psychiatry 2003;37:92-6.

- Pine DS, Cohen P, Gurley D, Brook J, Ma Y. The risk for early adulthood anxiety and depressive disorders in adolescents with anxiety and depressive disorder. Archives of General Psychiatry 1998;55:56-64.

- Price RA, Kidd KK, Weissman MM. Early onset (under age 30 years) and panic disorder as markers for etiologic homogeneity in major depression. Archives of General Psychiatry 1987;44:434-40.

- Reed V, Gander F, Pfister H, Steiger A, Sonntag H, Trenkwalder C, Hundt W, Wittchen H-U. To what degree does the Composite International Diagnostic Interview (CIDI) correctly identify DSMIV disorders? Testing validity issues in a clinical sample. International Journal of Methods in Psychiatric Research 1998;7:142-55.

- Roberst RE, Lewinsohn PM, Seeley JR. Symptoms of DSM-III-R Major Depression in adolescence: evidence from an epidemiological survey. Journal of the American Academy of Child and Adolescent Psychiatry 1995;34:1608-17.

- Robins E, Guze SB. Establishment of diagnostic validity in psychiatric illness: its application to schizophrenia. American Journal of Psychiatry 1970;126:983-7.

- Royall RM. Model robust confidence intervals using maximum likelihood estimators. International Statistical Review 1986;54: 221-6.

- Rush AJ, Weissenburger JE. Melancholic symptom features and DSM-IV. American Journal of Psychiatry 1994;151:489-98.

- Schreier A. Psychopathologie bei Kindern von Müttern mit einer Major Depression oder Angststörung: Ergebnisse zum familiären Auftreten psychischer Störungen aus einer Allgemeinbevölkerungsuntersuchung [Psychopathology in the children of mothers with

- major depression or anxiety disorders: results on the familial occurrence of mental disorders from a community study]. Technical University of Dresden, Germany, unpublished doctoral dissertation; 2005.

- Stancer HC, Persad E, Wagener DK, Jorna T. Evidence for homogeneity of major depression and bipolar affective disorder. Journal of Psychiatric Research 1987;21:37-53.

- StataCorp. Stata statistical software: release 8.2. College Station (TX): Stata Corporation; 2003.

- Sullivan PF, Neale MC, Kendler KS. Genetic epidemiology of major depression: review and meta-analysis. American Journal of Psychiatry 2000;157:1552-62.

- Türkçapar MH, Akdemir A, Örsel SD, Demirergi N, Sirin A, Kilic, EZ, Ösbay MH. The validity of diagnosis of melancholic depression according to different diagnostic systems. Journal of Affective Disorders 1999;54:101-7.

- Weiss B, Garber J. Developmental differences in the phenomenology of depression. Development and Psychopathology 2003;15:403-30. 
- Weissman MM, Wickramaratne P, Merikangas KR, Leckman JF, Prusoff BA, Caruso KA, Kidd KK, Gammon D. Onset of major depression in early adulthood. Increased familial loading and specificity. Archives of General Psychiatry 1984;41:1136-43.

- Weissman MM, Merikangas KR, John K, Wickramaratne P, Prusoff BA, Kidd KK. Familygenetic studies of psychiatric disorders. Developing technologies. Archives of General Psychiatry 1986a;43:1104-16.

- Weissman MM, Merikangas KR, Wickramaratne P, Kidd KK, Prusoff BA, Leckman JF, Pauls DL. Understanding the clinical heterogeneity of major depression using family data. Archives of General Psychiatry 1986b;43:430-4.

- Weissman MM, Warner V, Wickramaratne P, Prusoff BA. Early-onset major depression in parents and their children. Journal of Affective Disorders 1988;15:269-77.

- Weissman MM, Wolk S, Goldstein RB, Moreau D, Adams P, Greenwald S, Klier CM, Ryan ND, Dahl RE, Wickramaratne P. Depressed adolescents grown up. Journal of the American Medical Association 2003;281:1707-13.

- Wickramaratne PJ, Weissman MM. Onset of psychopathology in offspring by developmental phase and parental depression. Journal of the American Academy of Child and Adolescent Psychiatry 1998;37:933-42.

- Wickramaratne PJ, Greenwald S, Weissman MM. Psychiatric disorders in the relatives of probands with prepubertal-onset or adolescent-onset major depression. Journal of the American Academy of Child and Adolescent Psychiatry 2000;39:1396-405.

- Wittchen H-U, Pfister H. DIA-X Interviews: Manual für Screening-Verfahren und Interview; Interviewheft Längsschnittuntersuchung (DIA-X-Lifetime); Ergänzungsheft Querschnittsuntersuchung (DIA-X-12 Monate); Ergänzungsheft (DIA-X-12 Monate); PCProgramm zur Durchführung des Interviews (Längs- und Querschnittsuntersuchung); Auswertungsprogramm. Frankfurt: Swets \& Zeitlinger; 1997.

- Wittchen H-U, Perkonigg A, Lachner G, Nelson CB. Early developmental stages of psychopathology study (EDSP): objectives and design. European Addiction Research 1998a;4:18-27.

- Wittchen H-U, Lachner G, Wunderlich U, Pfister H. Test-retest reliability of the computerized DSM-IV version of the Munich-Composite International Diagnostic Interview (MCIDI). Social Psychiatry and Psychiatric Epidemiology 1998b;33: 568-78.

- Wittchen H-U, Lieb R, Schuster P, Oldehinkel T. When is onset? Investigations into early developmental stages of anxiety and depressive disorders. In: Rapoport JL, editor. Childhood

- onset of ,adult“ psychopathology, clinical and research advances. Washington (DC): American Psychiatric Press, Inc.; 1999. p. 259-302.

- Wittchen H-U, Kessler RC, Pfister H, Lieb R. Why do people with anxiety disorders become depressed? A prospective-longitudinal community study. Acta Psychiatrica Scandinavica 2000;102(Suppl. 406):14-23.

- Wittchen H-U, Beesdo K, Bittner A, Goodwin RD. Depressive episodes - evidence for a causal role of primary anxiety disorders? European Psychiatry 2003;18:384-93.

- World Health Organization. Composite International Diagnostic Interview (CIDI). Geneva: World Health Organization; 1990. 